Asian J. Med. Biol. Res. 2015, 1 (1), 47-52

\author{
Asian Journal of \\ Medical and Biological Research \\ ISSN 2411-4472 \\ www.ebupress.com/journal/ajmbr
}

\title{
Article \\ Prevalence of clinical diseases and disorders of goats at Upazila Livestock Development Center, Kapasia, Gazipur
}

\author{
Mohammad Ashraful Alam ${ }^{1 *}$, Mohammad Rohul Amin ${ }^{1}$, Torun Kumar Paul ${ }^{1}$, Tapu Kumar Saha ${ }^{1}$, Md. Khalilur \\ Rahman $^{1}$ and Md. Khalikuzzaman Rizon ${ }^{2}$ \\ ${ }^{1}$ Department of Physiology and Pharmacology, Patuakhali Science Technology University, Barisal-8210, \\ Bangladesh \\ ${ }^{2}$ Department of Agricultural Statistics, Bangladesh Agricultural University, Mymensingh-2202, Bangladesh
}

*Corresponding author: Mohammad Ashraful Alam, Department of Physiology and Pharmacology, Patuakhali Science and Technology University, Barisal-8210, Bangladesh. E-mail: ashraful00051@ gmail.com

Received: 17 May 2015/Accepted: 16 June 2015/ Published: 30 June 2015

\begin{abstract}
The study was conducted at Upazila Livestock Development Centre, Kapasia, Gazipur, during July, 2011 to December, 2011 to identify and determine the prevalence of clinical diseases and disorders of goats. A total number of 488 clinical cases of goats were recorded. Diagnosis of the clinical cases of goats were based on general examination (history and owner's complaint), physical examination of patient (inspection, palpation and percussion), clinical examination, microscopic examination and using common laboratory techniques. The clinical cases were divided into three groups on the basis of treatment required-medicinal, gynaeco-obstetrical and surgical cases. Among the three types of cases, medicinal cases 428(87.72\%) were highest followed surgical cases $43(8.80 \%)$ and gynaeco-obstetrical cases 17(3.48\%). Among the medicinal cases of goats, the contagious diseases PPR 32(6.56\%), black quarter 23(4.73\%) fascioliasis 77(15.78\%), diarrhoea 35(7.17\%), dysentery 30(6.15\%), ectoparasitism 30(6.15\%), paramphistomiasis 25(5.12\%), gastrointestinal nematodiasis $21(4.3 \%)$, fever 20(4.1\%) were recorded major disease problems in goats. Among the gynaeco-obstetrical cases, retained placenta $5(1.02 \%)$ and repeat breeding $12(2.46 \%)$ were recorded as major gynaeco-obstetrical problems in goats. Abscess $9(1.84 \%)$, castration 4(0.81\%), myiasis 10(2.05\%), navel-ill 7(1.43\%), gid disease $2(0.41 \%)$, urolithiasis $5(1.02 \%)$ and fracture $6(1.23 \%)$ were recognized as the main disorders which required surgical interventions. It may conclude that a number of diseases have been occurring in goats at study area and this report may help to develop strategies against major diseases reported in this study.
\end{abstract}

Keywords: goats; prevalence; diseases; medicinal; gynaeco-obstetrical; surgical

\section{Introduction}

Livestock is an integrated part of our farming system and plays an important role in the traditional economy of Bangladesh. Among the various constraints to cattle, buffaloes and goats production, diseases are the most important which degraded the productivity of these animals (Sarker et al., 1999).The economy of Bangladesh is mainly based on agriculture. About $80 \%$ of the population is employed in agriculture and livestock farming. Farmers are interested in rearing goats due to their polite behavior, low food intake, highest fertility rate (95\%) and multiple kidding efficiency(Islam, 1987).Livestock plays an important role in the development of the traditional economy of Bangladesh. Bangladesh is a densely populated agricultural country with an acute shortage of meat and milk. There are about 14.69 million goats in Bangladesh (DLS, 2008-2009). They provide mainly milk, meat, draught and hides and skins as important export item. The contribution of Livestock in 
Gross Domestic Product (GDP) is about $16.23 \%$ in Bangladesh (BBS, 2008).But livestock diseases and disorders of animals are the most important hindrance towards livestock development in our country. Most of the animals are weak, emaciated and non-satisfactory productive performance due to mainly malnutrition and diseases. Veterinary hospital is an ideal and reliable source of information about animal diseases and their solution. People from the neighboring areas bring their sick animals to the Veterinary hospital every day. Analysis of the case record gives a comprehensive idea about the disease problems at local areas. Although some reports on clinical case records from Bangladesh Agricultural University Veterinary Clinic (Rahman et al., 1972; Hossain et al., 1986; Das and Hashim, 1996; Samad, 2001; Samad et al., 2002), Haluaghat Upazila Veterinary Hospital, Mymensingh (Sarkeret al., 1999) and Dairy Cooperatives in Pabna district (Pharo, 1987), Ulipur Upazila Veterinary Hospital, Kurigram (Kabiret al., 2010), Chandanaish Upazila of Chittagong district, Bangladesh (Pallab et al., 2012) and Patuakhali Science and Technology University Veterinary Clinic (Rahman et al., 2012) were available but similar report on goats are very limited in Kapasia upazilla of Gazipur district of Bangladesh. This research works helps to describe the prevalence of clinical diseases and manifestations recorded in Upazila Livestock Development Centre, Kapasia, and Gazipur, Bangladesh during the period of from July, 2011 to December, 2011.

\section{Materials and Methods}

The study was performed at Upazila Livestock Development Center, Kapasia, Gazipur. A total 488 goats were examined during the period from July to December 2011. The general clinical examination was conducted according to the merit of cases and materials considered significant for laboratory diagnosis purposes were collected.

\subsection{General examination}

Physical condition, behavior, posture, gait, superficial skin wound, prolapsed of the uterus and vagina, salivation, nasal discharge, distension of the abdomen, locomotive disturbance etc were observed by visual examination of the patient.

\subsection{Physical examination}

Examination of different parts and system of the body of each of the sick animals were examined by using the procedures of palpation, percussion, auscultation, needle exploration, extension and flexion of limbs, use of mouth gag, local anesthesia and walking of animals as per methods described by Kelly (1979) and Samad (1988).

\subsection{Clinical examination}

Clinical examinations of all 401 goats of different ages were conducted on the basis of diseases history, owner complaint, symptoms, to diagnose the following diseases and disorders. History of each case (present and past) was carefully taken which gave a guideline for examination of the animals. According the merit of the individual case, general clinical examination were conducted on the basis of disease history and owners complaint, symptoms and techniques such as microscopic examination, common laboratory techniques used by Rosenberger (1979) and Samad et al.(1988). The temperature, pulse, and respiratory rate from each of these sick animals were recorded.These recorded clinical cases were primarily categorized into three major groups on the basis of treatment required. These groups were: (1) Medicinal cases, (2) Gynaeco-obstetrical cases and (3) Surgical cases. Medicinal cases were subcategorized as general systemic state, disease of the digestive system, respiratory system, urinary system, parasitic diseases, infectious diseases, non infectious diseases and diseases of the special sense organ. Surgical cases were subcategorized as (a) general surgery includes accidental injury, wound, abscess, cysts, myiasis, hoof trimming, dog bite wound (b) special surgery includes laparotomy, dehorning, urolithiasis, caesarean section, castration, rumenotomy and hernia (c) orthopedic surgery includes external fixation by using plaster of paris and internal fixation by using intramedullary pinning, dynamic compression plate (DCP). Gynae-obstetrical cases were subcategorized as (a) gynecological disorders includes anestrous, repeat breeder syndromes, pregnancy checkup and mastitis (b) Obstetrical diseases include abortion, dystocia and retain fetal membrane. These three groups that were considered sufficiently distinct so as to make clinical diagnosis accurate. However, the eye diseases of goat which are corneal opacity were included under medicinal cases because surgical intervention has never been practiced in Bangladesh recorded by Osmani et al. (2000). 


\section{Results and Discussion}

A total of 488 cases were recorded during the period starting from during the period from July to December 2011 under Upazila Livestock Development Center, Kapasia at Gazipur. The distribution of the different types of cases according to the class of goat is presented in Table 1.

Table 1. Overall distribution of different types diseases of goat.

\begin{tabular}{|l|l|l|l|}
\hline $\begin{array}{l}\text { Serial } \\
\text { No. }\end{array}$ & Diseases/disorders & No. of affected goats & Percentage (\%) \\
\hline 1 & Medicinal cases & 428 & 87.72 \\
\hline 2 & Surgical cases & 43 & 8.80 \\
\hline 3 & Gynaeco-obstetrical cases & 17 & 3.48 \\
\hline \multicolumn{2}{|c|}{ Total } & 488 & 100 \\
\hline
\end{tabular}

Medicinal cases 428 (87.72\%), surgical cases 43 (8.80\%), gynaeco-obstetrical cases 17 (3.48\%) from the total recorded clinical cases of sick goats (Table 1) which supports the earlier report of Rahman et al.(2012) who recorded $81.0 \%$ medicinal, 1.1\% gynaeco-obstetrical and $17.9 \%$ surgical cases in goats in Patuakhali Science and Technology University Veterinary Clinic, Babugonj, Barisal. This study also supports the report of Samad (2001) who recorded $76.91 \%$ medicinal, 3.67\% gynaeco-obstetrical and $19.42 \%$ surgical cases in goat during 1999 to 2001 from the Bangladesh Agricultural University (BAU) Veterinary Clinic, Mymensingh.

Anorexia was reported in $4.51 \%$ goats (Table 2). Prasad et al. (1980) recorded anorexia syndrome as one of the commonest problem amongst the non specific clinical entities in routine ruminant practice. Bloat is mainly a dietary in origin and occurs most frequently in ruminants in Bangladesh (Sutradhar et al., 2000). This study recorded $2.87 \%$ cases of bloat in goats (Table 2). The occurrence of bloat in goats supports the earlier finding of Rahman et al. (2012) who reported 2.5\% in goats and Samad (2001) reported 3.98\% prevalence of bloat in goats. Corneal opacity in goats was recorded $2.46 \%$ under this group (Table 2). Rahman et al. (2012) reported 9.9\% cases of corneal opacity in goats.

Diarrhoea was found to be the major digestive disorders in ruminants. Diarrhoea cases were $7.17 \%$ in goats (Table 2). These observations could be compared well with the $6.94 \%$ of non-specific diarrhoea $12.23 \%$ in goats (Hoque and Samad, 1996, 1997) and 12.1\% in goats (Rahman et al., 2012). Samad (2001) reported 9.91\% of diarrhoeal diseases in goats. Dysentery is characterized by inflammation of the intestine with evacuation of blood and mucus contained faeces, accompanied by tenesmus and colic. This disorder was recorded in $1.1 \%$ cattle and $6.15 \%$ goats (Table 2). Samad (2001) reported $1.87 \%$ dysentery in goats.

Analysis of the clinical cases $4.10 \%$ goats were affected with fever of unknown etiology. The percentages of occurrence of fever in this study support the earlier reports of $4.4 \%$ fever cases in goats (Hoque and Samad, 1997; Rahman et al., 2012). Pneumonia recorded in goats was 4.71\% (Table 2). Rahman et al. (2012) recorded $16.8 \%$ cases of pneumonia in goats.

The prevalence of different parasitic diseases was 15.78\% Fascioliasis, 5.12\% Paramphistomiasis, $4.30 \%$ Gastro-intestinal nematodiasis, 6.15\% Ectoparasites and 2.46\% Humpsore in goats (Table 2). The clinical prevalence of Paramphistomiasis recorded in goats has been reported from Bangladesh but detail studies on this disease have not yet been made from the country. But mange was recorded in 3.89\% goats (Table 2). Cases of mange in goats were comparatively higher than the reports of Samad (2001) who recorded $2.11 \%$ in goats where psoroptic mange in goat (Rahman et al., 1978) has been reported from Bangladesh.

This study recorded $6.56 \%$ cases of PPR in goats (Table 2). This finding support the finding of Rahman et al. (2012) who reported 5.2\% PPR cases in goats. This study recorded $4.10 \%$ cases of papillomatosis in goats (Table 2). Black quarter (BQ) was diagnosed on the presence of pronounced swelling of the affected muscles of upper limb with gaseous crepitation. BQ was recorded in $4.71 \%$ goats (Table 2). Mastitis $1.43 \%$ was diagnosed in does (Table 2). This study recorded $0.41 \%$ cases of tetanus in goats (Table 2). This finding support the finding of Samad (2001) and Rahman et al. (2012) reported 1.1\% cases in goats. Abscess was recorded in 1.84 $\%$ goats (Table 2). Rahman et al. (2012) reported 1.3\% goats affected with abscess at Patuakhali Science and Technology University Veterinary Clinic, Babugonj, Barisal and Samad (2001) who reported 1.56\% abscess cases in goats. 
Castration was recorded in $0.81 \%$ male kids (Table 2) where Samad (2001) recorded $2.03 \%$ castration cases in male kids. Myiasis was recorded in $2.05 \%$ goats (Table 2) where Rahman et al. (2012) who reported $16.4 \%$ goats affected with myiasis. Navel-ill was recorded only in $1.45 \%$ kids (Table 2 ).

Table 2. Prevalence of diseases and disorders goats at Upazila Livestock Development Center, Kapasia, Gazipur.

\begin{tabular}{|c|c|c|c|}
\hline Serial No. & Diseases & No. of affected goats & Percentage (\%) \\
\hline \multicolumn{4}{|c|}{ Medicinal cases } \\
\hline 1 & Anorexia & 22 & 4.51 \\
\hline 2 & Bloat & 14 & 2.87 \\
\hline 3 & Corneal opacity & 12 & 2.46 \\
\hline 4 & Digestive disorder (Diarrhoea) & 35 & 7.17 \\
\hline 5 & Dysentery (Coccidiosis) & 30 & 6.15 \\
\hline 6 & Fever & 20 & 4.10 \\
\hline \multirow[t]{2}{*}{7} & Respiratory disorder (Pneumonia) & 23 & 4.71 \\
\hline & Parasitic diseases & & \\
\hline 8 & Gastrointestinal nematodiasis & 21 & 4.30 \\
\hline 9 & Fascioliasis & 77 & 15.78 \\
\hline 10 & Paramphistomiasis & 25 & 5.12 \\
\hline 11 & Ectoparasitism & 30 & 6.15 \\
\hline 12 & Mange & 19 & 3.89 \\
\hline \multirow[t]{2}{*}{13} & Humpsore & 12 & 2.46 \\
\hline & Viral diseases & & \\
\hline 14 & PPR & 32 & 6.56 \\
\hline 15 & Rabies & 4 & 0.81 \\
\hline \multirow[t]{2}{*}{16} & Papillomatosis & 20 & 4.10 \\
\hline & Bacterial diseases & & \\
\hline 17 & Black quarter & 23 & 4.71 \\
\hline 18 & Mastitis & 7 & 1.43 \\
\hline \multirow[t]{2}{*}{19} & Tetanus & 2 & 0.41 \\
\hline & Sub-total & 428 & 87.70 \\
\hline \multicolumn{4}{|c|}{ Surgical cases } \\
\hline 20 & Abscess & 9 & 1.84 \\
\hline 21 & Castration & 4 & 0.81 \\
\hline 22 & Navel ill & 7 & 1.43 \\
\hline 23 & Myiasis & 10 & 2.05 \\
\hline 24 & Gid disease & 2 & 0.41 \\
\hline 25 & Urolithiasis & 5 & 1.02 \\
\hline \multirow[t]{2}{*}{26} & Fracture & 6 & 1.23 \\
\hline & Sub-total & 43 & 8.81 \\
\hline \multicolumn{4}{|c|}{ Gynaeco-obstetrical cases } \\
\hline 27 & Repeat breeders & 12 & 2.46 \\
\hline \multirow[t]{2}{*}{28} & Retained placenta & 5 & 1.02 \\
\hline & Sub-total & 17 & 3.48 \\
\hline \multicolumn{2}{|l|}{ TOTAL } & 488 & 100 \\
\hline
\end{tabular}

This observation supports the report of Samad (2001) recorded $0.62 \%$ navel-ill cases in kids. Gid disease was recorded only in two goats $0.41 \%$ (Table 2). Samad (2001) and Rahman et al. (2012) recorded 5.38\% and 2.5\% 
gid disease in goats respectively. Urolithiasis was recorded in $1.02 \%$ goats (Table 2). Fracture was recorded in 1.23\% goats (Table 3). Hossain et al. (1986) and Samad (2001) recorded 8.2\% and 1.1\% fracture cases among surgical conditions in goats respectively.

Retained placenta disorder was recorded only in $1.02 \%$ does (Table 2). Repeat breeders are those female ruminants that fail to conceive after three or more regularly spaced services in the absence of detectable abnormalities of the internal genitalia (Samad, 2000). This disorder was recorded in $2.46 \%$ goats (Table 2) whereas Samad (2001) reported $0.24 \%$ in goats.

\section{Conclusions}

This study was conducted to investigate the present situation of clinical diseases and disorders of goats at Kapasia upazila in Gazipur district. Goats were most susceptible to parasitic infestation then others diseases. This may be due to hilly and low land area and marshy grazing field and the farmers are not aware about the anthelmentic treatment of animals. The contagious diseases like as FMD and PPR were frequently outbreaks in this district. So, restriction of movement and frontier vaccination is necessary to control these types of diseases. Proper planning and program should be undertaken to prevent and control diseases and disorders in goats.

\section{Acknowledgements}

We thank to all honorable Upazila Livestock Officer Dr. Akhil Chandra for their best suggestion, constant encouragement, co-operation and their constant guidance and helped directly or indirectly during period of intern working in Upazila Livestock Development Centre, Kapasia, Gazipur.

\section{Conflict of interest}

None to declare.

\section{References}

BBS, 2008. Statistical year book on Bangladesh. Bangladesh Bureau Statistics, Ministry of Planning, Dhaka.

Das BC and MA Hashim 1996. Studies on surgical affections in calves. Bangladesh Veterinary Journal, 30: 53 57.

DLS, 2008-09. Annual Report of Directorate of Livestock Services, Bangladesh.

Hoque MS and MA Samad, 1996. Prevalence of clinical diseases in dairy cross-bred cows and calves in the urban areas in Dhaka. Bangladesh Veterinary Journal, 30: 118-129.

Hoque MS and MA Samad, 1997. Present status of clinical diseases of goats in the urban areas in Dhaka. Bangladesh Veterinary Journal, 31: 35-40.

Hossain MA, M Shaidullah and MA Ali, 1986. A report on surgical diseases and reproductive disorders recorded at the Veterinary Hospital of Bangladesh Agricultural University, Mymensingh. Bangladesh Veterinary Journal, 20: 1-5.

Kabir MH, MA Reza, KMA Razi, MM Parvez, MAS Bag and SU Mahfuz, 2010. A report on clinical prevalence of diseases and disorders in cattle and goat at the Upazilla Veterinary Hospital, Ulipur, Kurigram. International Journal of Biological Research, 2: 17-23.

Kelly WR, 1979. Veterinary Clinical Diagnosis, Second Ed.1974. Bailliere, Tandall and Cassel Ltd. London.39-102.

Osmani ABMMG, MA Hossain, MM Rahman and MR Alam, 2000. Corneal opacity in cattle: Prevalence and therapeutic evaluation of certain drugs. Bangladesh Veterinarian,17: 42-45.

Pallab MS, SM Ullah, MM Uddin and OF Miazi, 2012. A cross sectional study of several diseases in cattle at Chandanaish Upazilla of Chittagong district. Scientific Journal of Veterinary Advances, 1: 28-32.

Pharo HJ, 1987. Analysis of clinical case records from dairy co-operatives in Bangladesh. Trop. Anim. Health Prod.,19: 136-142.

Prasad J, SV Uoshi and A Rekib, 1980. Studies on the clinico-pathics of grazing animals in tropics-corneal opacity syndrome. Indian Vet. J., 57: 310-315.

Rahman A, MA Samad and MM Huq, 1978. Clinico-pathological studies on psoroptic mange in a goat. Bangladesh Veterinary Journal,13: 53-55.

Rahman MA, KM Ali and A Rahman, 1972. Incidence of diseases of cattle in Mymensingh. Bangladesh Veterinary Journal, 6: 25-30. 
Rahman MA, MA Islam, MA Rahman, AK Talukder, MS Parvin and MT Islam (2012). Clinical diseases of ruminants recorded at the Patuakhali Science and Technology University Veterinary Clinic. Bangl. J. Vet. Med., 10: 63-73.

Reosenberger A 1979. Preliminary observations of placental retention in cows. MedycynaWeterynaryji, 32:92.

Samad MA, 1988. Veterinary Clinicial Guide. $2^{\text {nd }}$ edn., Lyric-Epic Prokasoni, BAU Campus, Mymensingh, pp. $572-580$.

Samad MA, 2000. Veterinary Practitioner's Guide.1st Pub. No. 07, BAU Campus, Mymensingh.

Samad MA, 2001. Observations of clinical diseases in ruminants at the Bangladesh Agricultural University Veterinary Clinic. Bangladesh Veterinary Journal, 35: 93-120.

Sarker MAS, MA Hashim, MB Rahman and H Begum, 1999. Studies on bovine lymphadenitis syndrome. Bangladesh Veterinarian, 10: 6-8.

Sutradhar BC, MA Hossain and MR Alam, 2000. Incidence of bloat and it response to certain drugs in cattle. Bangladesh Veterinarian, 17: 37-41. 